\title{
Research on Emotional Leverage Effect of Capital Flow of Well-known Investment Institutions
}

\author{
Lilin $\mathrm{Li}^{1}$, Hanqiang $\mathrm{Liu}^{2}$ \\ ${ }^{1}$ Nanjing Audit University, Nanjing, Jiangsu, China \\ lll1399667179@163.com \\ ${ }^{2}$ School of Finance, Nanjing Audit University, Nanjing, Jiangsu, China \\ lhq668800@163.com
}

\begin{abstract}
China's capital market started late, compared with developed countries, China's individual investors account for a larger proportion. Because individual investor does not have the specialized investment knowledge and the mature investment psychology, its investment behavior often will receive the external factor the interference to produce "The herd effect", therefore, the well-known investor institutions can rely on the reputation effect brought by their own popularity to influence the stock price fluctuation by influencing the investor sentiment, thus exceeding the influence degree of the corresponding buying and selling fund flow. This paper defines the above process as the emotional leverage effect of well-known investment institutions. In this paper, we use principal component analysis to construct the index of investor sentiment, and use correlation test to find that the well-known investment institutions, by virtue of their own reputation, make their capital flow have a significant impact on investor sentiment, there is a significant positive correlation between investor sentiment and the fluctuation of individual stock prices in the industry. Small and medium-sized investors will suffer investment losses because of their blind faith in the trading strategies of well-known institutions. In order to further enhance the protection of investors' interests, this paper puts forward suggestions to improve the protection mechanism of small and medium-sized investors' rights and interests from the perspective of information disclosure and policy supervision.
\end{abstract}

Keywords: Investor sentiment, Noise trading, Emotional leverage, Credit quality.

\section{Introduction}

As a developing market with small and medium-sized investors as its main body, China's capital market has not perfect market environment and diversified investor structure, which leads to the existence of numerous "Follow-speculators" in China's financial market. Due to the lack of professional investment knowledge and research time and energy of listed companies, follow speculators often choose the trading strategies of well-known investment institutions in the market for securities investment. When a listed company discloses the company's announcement, once it is discovered that the company has been bought or even added positions by a wellknown institution in the market, follow the speculators will be listed on the company's performance and development prospects without analysis of the case blindly buy the company's secondary market shares, trying to "Copy work" way to obtain investment income.

The following traders believe that the information advantage of the investment institution is one of the reasons for the excess return in the capital market. When institutional investors sell the shares of listed companies, retail investors will have problems with the operation of the company so that the main institutions of Lenovo, one after another to sell securities held, this irrational behavior usually causes the investor to suffer the big investment loss.

Small and medium-sized investors on the company's overall operating conditions can only be obtained from the company's letter disclosure announcement, the disclosure of the quarterly statements of listed companies are not timely. "Some provisions on the reduction of shares held by shareholders and directors and supervisors of listed companies" stipulates that shareholders holding $5 \%$ of the company's shares must comply with the letter-covering procedure when selling the company's shares, but the red line of holding $5 \%$ of the listed company by a well-known investment institution has not been reached, the institutional share reduction need not be disclosed in the listed company, its investment behavior can not be timely and effectively understood by small and medium-sized investors. Small and medium-sized investors through institutional investors choose securities investment not only difficult to gain investment income, but will cause investment losses because of the volatility risk generated by Information asymmetry.

The main problem of this paper is whether the investment behavior of the well-known investment institution provides a positive signal for the small and medium-sized investors. The research results of this paper provide some suggestions for the small and medium-sized investors to choose their investment in the financial market, protect their interests in the complex and changeable financial market, and further improve the timeliness and effectiveness of the listed companies' letter investment, reduce overall Information asymmetry risk.

\section{Literature Review}

Bower (1981) and Black (1986) suggest that investor sentiment can lead to overoptimistic investors who invest in stocks or over pessimistic investors who sell stocks.

De Long, Shleifer et al (1990) in the DSSW model that noise traders in the financial market can be higher investment returns, according to the market efficiency theory, the market will adjust the securities prices based on information. However, the overreaction and underreaction of noise traders to information will increase the volatility of asset prices, and the rational investors are reluctant to accept higher risk premium and withdraw from the market because of risk aversion. Chen Nana (2010) draws a different conclusion 
through the empirical research, the Shanghai stock market does exist noise trading. Noise trading risks are particularly large, compared to investment profits, noise trading investors are more likely to bring losses.

Xu Yinxiang (2015) believes that the fluctuation of investor's sentiment will have a great impact on the stock market, and the asymmetric effect of stock price fluctuation can be taken as the reflection of noise trading's influence on the yield. Xing Hongwei and Wang Hanying (2021) replaced the irrational factors of the market with investor sentiment, and found that the risk of stock price collapse in the period of low investor sentiment was significantly higher than that in the period of high investor sentiment, and a negative premium on the risk of a slump exists only during periods of low investor sentiment.

Wang Yue (2016) uses the turnover ratio, P/E ratio and noise coefficient to measure the noise trading in the Chinese and American securities markets, and finds that the fluctuation in the Chinese

market is caused by noise trading, noise trading is not the cause of market volatility in the United States. Chen Jian and Zeng Shiqiang (2018) found that investors' optimism and pessimism will make the stock volatility increase, while margin trading mechanism will weaken the impact of investor sentiment on the stock volatility.

Yao (2020) uses principal component analysis (PCA) to construct the investor sentiment of a shares, and then uses the hot path method to study the sentiment and the lead-lag structure of the stock market. The empirical results show that, in the short run, investor sentiment leads the stock market, but in the long run, it is the stock market fluctuation that influences the investor sentiment. $\mathrm{Hu}$ Changsheng, Chi Yangchun (2012) take the investor wealth maximization as the emotion index choice standard, extracts the market sentiment index from the turnover rate, the Closed-end fund discount rate, the new investor opens the account number and the Consumer Confidence Index. Zhang Zongxin, Wang Hailiang (2013) on the basis of the existing research on the number of new shares rose and fell the ratio and $\mathrm{P} / \mathrm{E}$ ratio of two subindicators to build an investor sentiment index. The empirical results show that the fitting precision of composite index is better than that of single index, and it can reflect the change of market sentiment more truly and comprehensively.

In conclusion, we can find that the fluctuation of investor's emotion will lead to the risk of market fluctuation, and investors will be hurt by irrational behavior. From the perspective of the influence of the capital flow of well-known institutions on investor sentiment, this paper explores whether small and medium-sized investors can obtain positive investment returns by following institutional investors in securities investment, this paper puts forward the investor protection mechanism under the market environment of the Information asymmetry, and further consummates the policy supervision of the supervisory department to the market organization.

\section{Variable Selection and Emotion Construction}

Based on the daily trading data from Feb. 1,2020 to March 31,2020 , this paper analyzes the impact of institutional fund flows in the gaming industry on investor sentiment.

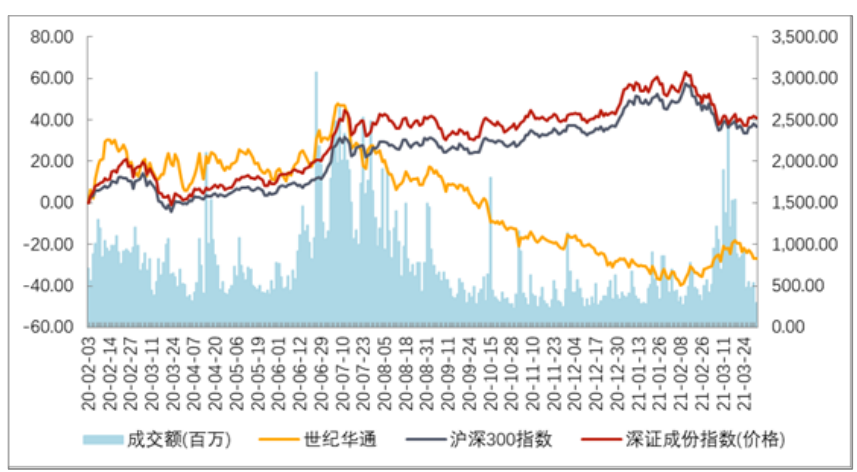

Figure 1: Century Huatong stock price trend chart

As a leader in the gaming sector, St Century Houa Thong has long been a favourite of institutional investors. In 2020, due to the outbreak of new crown disease, "Homestead economy" suddenly emerged, the game plate stood on the wind to become the darling of the market, Century Huatong because of its good performance by institutional investors Gao Yi Adjacent Hill No. 1 Yuanwang Fund Jancang buy. According to the 2020 Quarterly Report of Centuryhuatong, the Gao Yi Fund has built a position in Centuryhuatong. Under the circumstances of large fluctuations in the foreign financial markets, Centuryhuatong has conducted additional positions and made large subscriptions in the Centuryhuatong directional additional issue, century Huatong semi-annual report shows that as of June 30,2020, Gao Yi Fund in the century Huatong Top 10 outstanding shareholders, sending a strong positive signal for the enterprise. As a well-known fund in the market, its large-scale buying behavior has attracted a large number of small and medium-sized investors to buy Centuryhuatong in order to follow the investment of professional investment institutions to obtain rich returns. However, the disclosure of quarterly reports of listed companies in China is often time-delayed, and the information it discloses can not reflect the current situation of enterprises in time. According to Century Huatong's third quarter 2020 report, Gao Yi's fund reduced its holdings after July when small and medium sized investors rushed to buy century Huatong shares. Since Gao Yi's holdings are less than 5\% of the company's total, it does not have to comply with the letter disclosure rules, when the third-quarter results were announced, the small and medium-sized investors who followed suit and bought century Houa Thong suffered big losses.

The Information asymmetry has left small and medium-sized investors with poor expectations for Houa Thong's prospects in the ST century. Since then, due to the emotional leverage of institutional capital flows, small and medium-sized investors have become overly pessimistic about century hua tong. Despite the good fundamentals, the stock price has dropped more than $50 \%$ at its peak, and investors have suffered heavy investment losses. According to this phenomenon, this paper raises a research question: does the investment behavior of 
well-known investment institutions provide a positive signal for small and medium-sized investors? Whether its liquidity has increased the emotional leverage of the market. In order to verify the reliability of the conclusion, this article also selects the perfect world (002624) to carry on the supporting analysis.

\subsection{Variable Selection}

In order to better measure individual stock investor sentiment, this article selects individual stock trading volume, turnover rate, margin and securities lending margin and capital flow from stock trading information as sub-indicators to measure investor sentiment.

Volume: The number of stocks bought plus the number of stocks sold constitutes the stock's trading volume on the day

Turnover rate: trading volume/tradable equity*100\%

Margin and securities lending difference: divided into financing difference and securities lending difference. The financing difference is the balance of daily financing purchases and repayments, and the securities lending difference refers to the difference between daily securities selling and selling and repayment.

Funds flow: this indicator is composed of small order inflow funds, small order outflow funds, super large order net inflow funds and main force net inflow funds. The above data are all sourced from the Choice financial data terminal, and are all standardized. Market sentiment can be reflected by the total trading volume of securities.

The above four indicators can comprehensively reflect the total trading volume of securities, so we choose to construct an investor sentiment indicator.

$\mathrm{SENT}=\beta_{1} *$ Zscore $($ Volume $)+\beta_{2} *$ Zscore $($ Turnover rate $)+$ $\beta_{3} *$ Zscore:Small single inflow of funds $+\beta_{4} *$ Zscore: Small single outflow $+\beta_{5} *$ Zscore : (Margin and securities lending difference) $+\beta_{6} *$ Zscore: Main net inflow of funds $+\beta_{7}$ *Zscore: Large single net inflow of funds

\subsection{Construction of Sentiment Index}

First, perform correlation analysis on the above data to preliminarily determine the necessity of data dimensionality reduction. The correlation test results are as Table 1 shows.

It can be seen from the Table 1 that there is a significant correlation between the variables selected in this article, so the principal component analysis method needs to be used to reduce the dimensionality of the data. In this paper, the principal component analysis results of the above standardized variables are as Table 2 shows:

Table 1: The correlation test results

\begin{tabular}{|c|c|c|c|c|c|c|c|}
\hline & Volume & $\begin{array}{l}\text { Turnover } \\
\text { rate }\end{array}$ & $\begin{array}{l}\text { Main net } \\
\text { inflow of } \\
\text { funds }\end{array}$ & $\begin{array}{l}\text { Small } \\
\text { single } \\
\text { outflow }\end{array}$ & $\begin{array}{l}\text { Small } \\
\text { single } \\
\text { inflow of } \\
\text { funds }\end{array}$ & $\begin{array}{l}\text { Large } \\
\text { single net } \\
\text { inflow of } \\
\text { funds }\end{array}$ & $\begin{array}{c}\text { Margin } \\
\text { and } \\
\text { securities } \\
\text { lending } \\
\text { difference }\end{array}$ \\
\hline Volume & 1 & $.857 * *$ & $-.346 * *$ & $.843 * *$ & $.849 * *$ & $-.263^{* *}$ & $.150 *$ \\
\hline Turnover rate & $.857 * *$ & 1 & $-.290 * *$ & $.821 * *$ & $.873 * *$ & $-.159 * *$ & $-.251 * *$ \\
\hline Main net inflow of funds & $-.346^{* * *}$ & $-.290 * *$ & 1 & $-.647 * *$ & -0.1 & $.934 * *$ & $-.134 *$ \\
\hline Small single outflow & $.843^{* *}$ & $.821 * *$ & $-.647 * *$ & 1 & $.812 * *$ & $-.523^{* *}$ & 0.093 \\
\hline Small single inflow of funds & $.849 * *$ & $.873 * *$ & -0.1 & $.812 * *$ & 1 & 0.008 & -0.022 \\
\hline Large single net inflow of funds & $-.263^{* *}$ & $-.159 * *$ & $.934 * *$ & $-.523^{* *}$ & 0.008 & 1 & $-.172 * *$ \\
\hline Margin and securities lending difference & $.150 *$ & $-.251 * *$ & $-.134 *$ & 0.093 & -0.022 & $-.172 * *$ & 1 \\
\hline \multicolumn{8}{|c|}{ ** At the 0.01 level (two-tailed), the correlation is significant. } \\
\hline$*$ At the 0.05 level (two-tailed & elation is & ificant. & & & & & \\
\hline
\end{tabular}

Table 2: The KMO and Bartlett test results

\begin{tabular}{|c|c|c|c|c|c|c|}
\hline \multicolumn{7}{|c|}{ KMO and Bartlett test } \\
\hline \multicolumn{3}{|c|}{ KMO sampling appropriateness quantity } & & & & 0.603 \\
\hline \multicolumn{3}{|c|}{ Bartlett sphericity test } & \multicolumn{3}{|c|}{ Approximate chi-square } & 2970.327 \\
\hline & & & \multicolumn{3}{|c|}{ Degree of freedom } & 21 \\
\hline & & & \multicolumn{3}{|c|}{ Significance } & 0 \\
\hline \multirow[t]{2}{*}{ ingredient } & \multicolumn{3}{|c|}{ Initial eigenvalue } & \multicolumn{3}{|c|}{ Extract the sum of squares of the load } \\
\hline & total & Variance & Cumulative $(\%)$ & total & Variance & Cumulative $(\%)$ \\
\hline 1 & 3.892 & 55.60 & 55.60 & 3.89 & 55.60 & 55.6 \\
\hline 2 & 1.829 & 26.13 & 81.73 & 1.82 & 26.13 & 81.7 \\
\hline 3 & 1.015 & 14.49 & 96.23 & 1.01 & 14.49 & 96.2 \\
\hline 4 & 0.143 & 2.042 & 98.27 & & & \\
\hline 5 & 0.071 & 1.013 & 99.28 & & & \\
\hline 6 & 0.042 & 0.595 & 99.88 & & & \\
\hline 7 & 0.008 & 0.119 & 100 & & & \\
\hline
\end{tabular}

It can be seen from the KMO and Bartlett test results table that the KMO sampling appropriateness of the dimensionality reduction result reaches 0.603 , and the sphericity test result is significant; the variance explanation table shows that when the principal component analysis method selects the first three principal components, The cumulative interpretation of the overall variance reached $96.23 \%$. In summary, the principal component analysis result can be used as a good substitute for multiple sub-indices. The principal component score matrix is as Table 3 shows. 
Table 3: The principal component score matrix

\begin{tabular}{|c|c|c|c|}
\hline & & & \\
\hline Component score coefficient matrix & ingredient & \\
\hline & 1 & 2 & 3 \\
\hline Zscore Volume & 0.234 & 0.116 & 0.207 \\
\hline Zscore Turnover rate & 0.227 & 0.212 & -0.171 \\
\hline Zscore Small single inflow of funds & 0.252 & -0.031 & 0.018 \\
\hline Zscore Small single outflow & 0.213 & 0.272 & 0.14 \\
\hline Zscore Margin and securities lending difference & 0.014 & -0.213 & 0.904 \\
\hline Zscore Main net inflow of funds & -0.157 & 0.408 & 0.207 \\
\hline Zscore Large single net inflow of funds & -0.13 & 0.448 & 0.184 \\
\hline
\end{tabular}

Suppose the first three principal components are F1, F2, and F3, and their corresponding weights are the proportions of this component in all components, and the expression of individual stock investor sentiment (SENT) can be obtained: Suppose the first three principal components are F1, F2, and F3, and their corresponding weights are the proportions of this component in all components, and the expression of individual stock investor sentiment (SENT) can be obtained:

SENT $=0.179372987 *$ Zscorevolume $+0.044888491 *$ Zscoretu rnoverrate $+0.045851521 *$ Zscore small order inflow funds $+0.201912045^{*}$ Zscore small order outflow funds $+0.327084675^{*}$ Zscore margin financing and securities lending difference +0.208765057 Z Zscore main net inflow funds $+0.218265355^{*}$ Zscore Large single net inflow of funds

\subsection{Applicability Analysis}

In order to test the applicability of investor sentiment, it is necessary to analyze the correlation between it and the volatility of individual stock returns. If investor sentiment does affect the investor's investment decision on individual stocks, there will be a significant correlation between the two, that is, investment There is a significant correlation between investor sentiment and the volatility of individual stock returns. The test results are as Table 4 shows.

Table 4: The test results

\begin{tabular}{|c|c|c|c|}
\hline & & Volatility & sentiment \\
\hline Volatility & Pearson correlation & 1 & $.446^{* *}$ \\
\hline & Significance (two-tailed) & & 0 \\
\hline & Number of cases & 285 & 285 \\
\hline sentiment & Pearson correlation & $.446^{* *}$ & 1 \\
\hline & Significance (two-tailed) & 0 & \\
\hline & Number of cases & 285 & 285 \\
\hline \multicolumn{2}{|r|}{$\begin{array}{c}\text { ** At the } 0.01 \text { level (two-tailed), the } \\
\text { correlation is significant. }\end{array}$} & & \\
\hline
\end{tabular}

It can be seen from the Table 4 that there is a significant positive correlation between investor sentiment in this stock and stock return volatility, which shows that the sentiment index has good applicability and can reflect investor sentiment changes to a certain extent.

In order to test the robustness of the sentiment index, this paper selects another stock in the same industry perfect world to test the applicability of the index. The Perfect World data is used to reconstruct the individual stock sentiment index, and the relevance test is carried out to test whether the applicability of the investor sentiment index is robust. The results are as Figure 1 shows.

According to the Figure 1, the sampling fitness of KMO is
0.648, the spherical test results are significant, and the correlation analysis shows a significant positive correlation with the closing price fluctuation, it shows that the method of measuring investor sentiment has stable applicability.

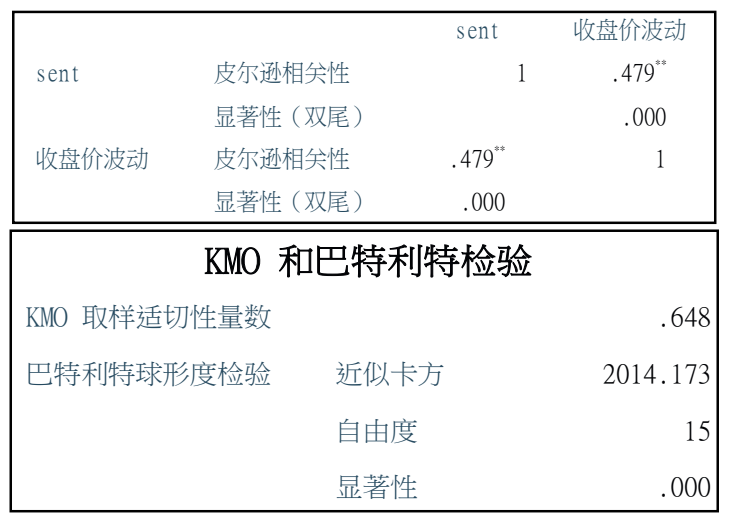

Figure 1: The KMO and Bartlett test results

\section{Empirical Test}

\subsection{Causality Test between Investor Sentiment and Stock Price Volatility}

In order to further verify the relationship between investor sentiment and stock price volatility, this paper conducts Granger causality test between individual stock investor sentiment and stock price volatility. The test results are as Table 5 shows.

Table 5: The test results of Granger causality test

\begin{tabular}{|c|c|c|c|}
\hline Null Hypothesis: & Obs & F-Statistic & Prob. \\
\hline SENT does not Granger Cause SIGMA & 283 & 12.72612 & 0.0000 \\
\hline SIGMA does not Granger Cause SENT & 11.0339 & 0.0000 \\
\hline
\end{tabular}

According to the results of Granger test, individual stock investor sentiment index and stock closing price volatility have a Granger causal relationship, indicating that investor sentiment can lead to increased stock price volatility, and stock price volatility intensifies changes in investor sentiment. There is a mutually reinforcing relationship between the people.

\subsection{Tests on the Influence of Well-Known Investment Institutions on Investor Sentiment}

If the withdrawal of well-known institutional investors can affect investor sentiment, the existing investor sentiment and stock price fluctuations can be used to spread to the channel, which can have an impact on stock price fluctuations that exceed the amount of free funds, that is, there is an imitation effect due to investment. The emotional leverage brought. 


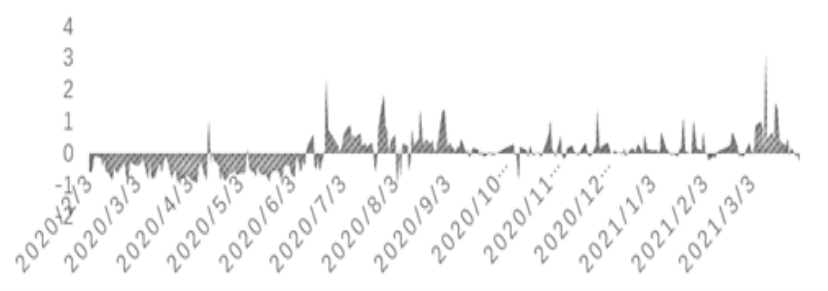

Figure 2: The cure of emotional leverage

It can be seen intuitively from the Figure 2 that the sentiment of individual stock investors has changed significantly in July, and this point of time happened to be the time node of the institution's withdrawal from Century Huatong. Therefore, this article uses this time node as the dividing line. Investor sentiment is divided into two sections and the differences are analyzed.

Table 6: The descriptive statistics

\begin{tabular}{|c|c|c|c|c|}
\hline Variable & Count & Mean & Std. Dev. & $\begin{array}{c}\text { Std. Err. of } \\
\text { Mean }\end{array}$ \\
\hline AFTER & 101 & 0.207862 & 0.428429 & 0.04263 \\
\hline BEFORE & 101 & -0.42411 & 0.450805 & 0.044857 \\
\hline All & 202 & -0.10812 & 0.541082 & 0.03807 \\
\hline \multicolumn{2}{|c|}{ Method } & df & Value & Probability \\
\hline \multicolumn{2}{|c|}{ t-test } & 200 & 10.21238 & 0 \\
\hline Satterthwaite-Welch t-test* & 199.4838 & 10.21238 & 0 \\
\hline \multicolumn{2}{|c|}{ Anova F-test } & $(1,200)$ & 104.2928 & 0 \\
\hline \multicolumn{2}{|c|}{ Welch F-test* } & $(1,199.484)$ & 104.2928 & 0 \\
\hline
\end{tabular}

From the descriptive statistics, we can intuitively see that the investor sentiment before July (before) and the investor sentiment after July (after) have a significant difference in the mean, and then the mean test between the two series shows that the two series The difference between the mean values is significant. Therefore, it can be considered that the emotional leverage of well-known institutional investors exists and the effect is obvious.

\section{Conclusions}

As a developing market with small and medium-sized investors as the main body, the protection of the legitimate interests of small and medium-sized investors is related to the distribution of wealth and social equity, and has been a hot issue of social concern. This paper constructs the Index of investor sentiment by principal component analysis, and the correlation test shows that the fund flow of well-known investment institutions has a significant impact on investor sentiment, and the investor sentiment has a significant positive correlation with the stock price of individual stocks in the industry, small and medium-sized investors will be blind to the trading strategies of well-known institutions suffer investment losses. Therefore, small and medium investors need to improve their investment literacy, investment needs to have a more basic understanding of the Fundamental analysis can prevent investors blindly follow the trade brought about by the huge losses. Institutional investors need to improve their professional ethics, strengthen the management of fund managers' behavior, establish compliance standards, and create a good market environment.

The capital flow of well-known institutions will increase the market sentiment of small and medium-sized investors. The fundamental reason is the fear of unknown information of small and medium-sized investors brought about by Information asymmetry. In order to reduce the investment risk brought by the fluctuation of investor sentiment, it is necessary to take measures to improve the quality and effectiveness of the listed companies. Regulators need to introduce policies to boost board and secretary platforms' responses to investors' concerns, penalize companies that fail to respond and delay responding to investors' concerns, and boost investors' confidence in capital markets. It is necessary to strengthen the education of professional ethics for noncompliant institutional investment, to make small and medium-sized investors accountable for their loss of interests, and to strengthen the protection mechanism for investors' interests.

\section{Acknowledgement}

The paper is supported by the project: 2021 Postgraduate Research and Innovation Project of Jiangsu Province, project number: SJCX21_0812.

\section{References}

[1] Black F, Cox J C. Valuing Corporate Securities: Some Effects of Bond Indenture Provisions[J]. Journal of Finance, 1976, 31(2): 351-367.

[2] Bower, Gordon H. Mood and memory[J]. Am Psychol, 1981, 36(2): 129-148.

[3] Long J D, Shleifer A, Summers L H, et al. Noise Trader Risk in Financial Markets[J]. Scholarly Articles, 1990.

[4] Chen Nana. The application of noise trading theory in Chinese stock market [D]. Northwest A\&F University, 2010.

[5] Chen Jian, Tsang Sai Keung. Research on the influence of investor sentiment on stock price fluctuation $[\mathrm{J}]$. Price Theory and Practice, 2018(07): 99-102.

[6] Shen Baoxi. Study on the correlation between investor sentiment and stock market returns [J]. Agricultural economics of Shanxi, 2021(01): 190-192.

[7] Xu Yinxiang. The impact of noise trading on return in Chinese stock market [D]. Fujian Normal University, 2015.

[8] Wang Chenglong and Wang Xi. Research on quantitative investment strategy based on investor sentiment [J]. China Prices, 2021(03): 82-85.

[9] Wang Yue. A comparative study of noise trading in Chinese and American stock markets. Northwest A\&F University, 2016.

[10] Xing Hongwei, Wang Hanying. Analysis of inducing factors of stock price collapse [J/OL]. Systems Engineering: 1-18.

[11] Hu Changsheng, Chi Yangchun. Investor sentiment: Rationality versus irrationality $[\mathrm{J}]$. Financial Review, 2012, 4(06): 46-62+122.

[12] Zhang Zongxin and Wang Hailiang. Investor sentiment, subjective belief adjustment and market fluctuation [J]. Financial Research, 2013(04): 142-155. 